\title{
Porn Sex versus Real Sex: Sexual Behaviors Reported by a U.S. Probability Survey Compared to Depictions of Sex in Mainstream Internet-Based Male-Female Pornography
}

\author{
Niki Fritz ${ }^{1}\left[\right.$ ] Vinny Malic ${ }^{2} \cdot$ Tsung-chieh Fu $^{3} \cdot$ Bryant Paul $^{1} \cdot$ Yanyan Zhou $^{1} \cdot$ Brian Dodge $^{3} \cdot$ J. Dennis Fortenberry ${ }^{4}$ \\ Debby Herbenick ${ }^{3}$
}

Received: 12 July 2019 / Revised: 4 October 2021 / Accepted: 5 October 2021 / Published online: 14 February 2022

(c) The Author(s), under exclusive licence to Springer Science+Business Media, LLC, part of Springer Nature 2022

\begin{abstract}
Using data from a 2014 U.S. nationally representative probability survey and a 2014 content analysis of 2562 male-female videos from two popular pornographic websites, this study aimed to: (1) compare the prevalence of survey respondents' eventlevel sexual behaviors with those depicted in mainstream pornography online videos; (2) compare event-level condom use with condom use prevalence in pornographic videos; (3) compare event-level orgasm with prevalence of orgasms in pornographic videos; and (4) assess whether respondents' partnered use of pornography was associated with the sexual behaviors in which they report engaging. We found that kissing, male orgasm, female orgasm, and condom use were significantly less prevalent in the pornographic videos than in survey respondents' most recent sexual experiences. Conversely, penile-anal intercourse and fellatio were significantly more prevalent in the pornographic videos than in participants' reports of their most recent sexual experience. There were no significant differences between the prevalence of cunnilingus or sex toy use represented in the videos as compared to survey respondents' reports. Finally, we found that individuals who reported partnered pornography use during their most recent sexual experience were more likely to report having engaged in oral sex, penile-anal intercourse, and sex toy use and were also more likely to report female orgasm during their most recent sexual experience.
\end{abstract}

Keywords Pornography $\cdot$ Sexual behaviors $\cdot$ Condom use $\cdot$ Orgasm

\section{Introduction}

People watch pornography for numerous reasons including to enhance their sexual arousal, facilitate masturbation, learn the mechanics of sex, enjoy themselves, improve their relationships, relieve boredom, see people like themselves represented, confirm one's sexual orientation identity, or because their partner wants them to (Arrington-Sanders et al., 2015;

Niki Fritz

nrfritz@iu.edu

1 The Media School, Indiana University-Bloomington, $601 \mathrm{E}$ Kirkwood Ave., Bloomington, IN 47405, USA

2 School of Informatics, Computing, and Engineering, Indiana University-Bloomington, Bloomington, IN, USA

3 Center for Sexual Health Promotion, Indiana University School of Public Health, Bloomington, IN, USA

4 Division of Adolescent Medicine, Indiana University School of Medicine, Indianapolis, IN, USA
Litsou et al., 2021; Paul \& Shim, 2008; Smith et al., 2015). Although pornography has long been the subject of controversy (Bronstein, 2011; Heins, 2007), in recent years there has been greater attention to the potential public health implications of pornography use, with scholars noting that pornography use does not meet the definition of a public health crisis (McKay et al., 2021; Nelson \& Rothman, 2020). That said, prior research has examined the role of pornography in larger contexts of sexual health and public health issues, for example in terms of associations with sexual aggression (Allen et al., 1995; Hald et al., 2010; Oddone-Paolucci et al., 2000; Wright et al., 2015a, 2015b; Wright \& Tokunaga, 2016), earlier sexual debut (Brown \& L'Engle, 2009), transactional sex (Hald, et al., 2013), and condomless sex (Tokunaga et al., 2020; Wright et al., 2016, 2018). However, other research suggests that some of these potential relationships may be attenuated in the presence of other factors. For example, adolescents who watch pornography are less likely to have condomless sex if their parents have talked with them about condoms, birth control, and/or sexually transmitted 
infections (STI), underscoring the importance of examining the broader context in which adolescent sexual behavior exists (Wright et al., 2020).

Along these lines, some research has considered whether and how pornography literacy programs may be able to support adolescents and young adults in developing a healthier sense of their own sexuality (Dawson et al., 2020). Some pornography literacy programs attempt to do so by helping young people to think critically about the pornography they've viewed, increasing their awareness that pornography tends to be unrealistic in a number of ways whether in terms of heteronormative themes, the kinds of bodies that are centered, and the sexual behaviors depicted (Baams et al., 2015; Dawon et al., 2020; Vandenbosh \& van Oosten, 2017). One assumption of some pornography literacy programs is that sexual behaviors in pornography are significantly different compared to the sexual behaviors common to people's actual sexual lives. Several popular media highlight this perceived gap between what is framed as "real sex" and "porn sex" including Gallop's (2009) TED Talk titled "Make love, not porn," and the Youtube video titled "Porn Sex vs Real Sex: The Differences Explained with Food" (KB Creative Lab, 2013), the latter which has been viewed more than 19 million times as of this writing. However, there has been no empirical research comparing population-level sexual behaviors with those depicted in porn, which is what the present research aims to do.

In addition to examining associations for pornography at the individual level, some research also considers pornography use within relational contexts, often finding that pornography use may be associated with decreased couples' sexual and relationship satisfaction as well as decreased commitment (Maas et al., 2018; Oddone-Paolucci et al., 2000; Rasmussen, 2016; Wright et al., 2017). The acquisition, activation, and application model $\left({ }_{3} \mathrm{AM}\right)$ indicates that the congruency between media depictions and reality, or the script-situation correspondence, may increase the likelihood of script activation and application (Wright, 2011). If sexual partners consume pornography together just before or during sex, ${ }_{3} \mathrm{AM}$ would suggest the script-situation correspondence would increase activation and possibly application of the behaviors depicted in pornography. There has been little research, however, on the association of dyadic use of pornography and partners' sexual repertoire (e.g., the sexual behaviors in which they engage together).

\section{What Is Pornography, Who Is Watching It, and Why?}

Previous scholarship has defined pornography as material that enhances sexual arousal and which also includes explicit depictions of genitalia and sexual acts (Hald, 2006), whereas mainstream pornography has been defined as material created not only for sexual arousal, but also for mass markets and to make a profit (Corsianos, 2007). Research suggests that pornography is now accessed in the USA more often via the Internet as compared to print, video/DVD, or television sources (Hald et al., 2013). In one 2016 US nationally representative study, men reported accessing pornography from a broader range of media than did the women participants (Herbenick et al., 2020); the men also reported more frequent viewing of pornography and having viewed more genres than had women. Xvideos. com and Pornhub.com are two of the most accessed mainstream online streaming pornography sites in the world and in the USA. As an example, in 2014 (the year for which we analyzed both survey data and pornographic videos) there were 18.4 billion visits to Pornhub and 78.9 billion videos were viewed on that site (Pornhub 2014 Year in Review, 2015). On both sites content is free, giving consumers easy access to mainstream pornography via the internet.

The percentage of Americans who report having recently consumed pornography varies by study, depending on item phrasing (Regnerus et al., 2016). These researchers estimated that $36 \%$ of men and $16 \%$ of women ages 18-39 years had consumed pornography in the prior week. Although the researchers noted this is higher than earlier population-representative surveys, it is also lower than some surveys within specific demographic categories. For example, using 23 waves of data from the General Social Survey, Wright et al. (2013) found that while only $17 \%$ of women, on average, reported having seen "an X-rated film in the past year," $34 \%$ of women ages 18-30 answered affirmatively to the same question, indicating that more younger women may generally view pornography.

Research suggests a substantial proportion of Americans view pornography, although their motivations may vary by consumers' gender, age group, culture, or other identities. Some research has suggested that there are four broad motivations for consuming pornography including using pornography for fantasy, habitual use, mood management, and as part of a relationship (Paul \& Shim, 2008). A large study of individuals aged 18-65 found that people consumed pornography to fulfill sexual needs, but also to reduce stress and boredom and to facilitate orgasm (Smith et al., 2015). Researchers have also found that young people may use pornography to explore their sexual identities or as a sexual outlet (Attwood et al., 2018). A recent study found similar results, although participants also noted perceptions of potential harm from pornography use (Davis et al., 2020). Also, some individuals may consume pornography in group viewing settings to help them understand social sexual norms (Löfgren-Mårtenson \& Månsson, 2010). Notably, pornography consumers rarely indicate that they consume pornography specifically to learn how to have sex, though young adults may find pornography to be more helpful in terms of learning about sex as compared to adolescents 
(who more commonly name their parents or peers as helpful sources of information) (Rothman et al., 2021). Indeed, some people believe that watching pornography positively contributed to their sexual knowledge (Hald \& Malamuth, 2008), suggesting that at least some consumers believe they are gaining sexual information from pornography.

\section{Pornography Literacy Programs and Perceived Realism of Pornography}

Although pornography consumers do not often report sexual knowledge as their primary motivation for viewing pornography, some studies suggest that individuals, especially those who already use the internet for pornography, may more often seek sexual advice online (Luder et al., 2011). Some qualitative research also suggests that adolescents may intentionally use pornography for instructional purposes, attempting to replicate the sexual behaviors they view in their own lives, even if such education is not their primary purpose of consumption (Rothman et al., 2015). Indeed, the lack of comprehensive sexual health education in the USA — and a particular dearth of sexuality education related to pleasure and exploration-may encourage young people to seek out sexual information from diverse sources and especially on the internet, which is easily accessible, free, and has a sense of anonymity (Lindberg et al., 2016; Simon \& Daneback, 2013).

Recently, and in acknowledgement of this sex education gap, researchers have explored pornography literacy programs as a potential tool support to young people in their sexual development (Dawson et al., 2020; Vandenbosch \& van Oosten, 2017). Pornography literacy programs attempt to decrease participants' perceived realism of pornography by identifying its unrealistic sexual depictions (Dawson et al., 2020). Research suggests perceived realism may mediate the relationship between pornography use and sexual health behaviors such as condomless sex (Wright et al., 2018), instrumental views of sex (Peter \& Valkenburg, 2010), and permissive sexual attitudes (Baams et al., 2015). Although research on pornography literacy programs is relatively new, one small study found that participants in a nine-session pornography literacy program decreased their perceived pornography realism (Rothman et al., 2020). Given the importance of evidence-based information to sexuality education, pornography literacy programs may be enhanced by empirical research that examines how the sexual behaviors depicted in porn do or do not reflect "real life" sexual behaviors.

\section{Depictions of Sexual Behaviors in Pornography}

Prior content analyses have illustrated several patterns relating to the depiction of sexual behaviors across mainstream pornographic content sources. In general, oral sex and penile-vaginal intercourse have been identified as the most prevalent sexual behaviors in pornography (Bridges et al., 2010). Multiple studies of online and paid DVD male-female pornography have found fellatio to be commonly depicted, present in $79 \%$ to $90 \%$ of scenes (Bridges et al., 2010; Gorman et al., 2010). Indeed, fellatio tends to be depicted about twice as often as cunnilingus, suggesting a sexual script that prioritizes fellatio over oral sex reciprocity between male-female partners (Bridges et al., 2010; Gorman et al., 2010; Klaassen \& Peter, 2015; Vannier et al., 2014). Additionally, penile-vaginal intercourse has been found in more than $80 \%$ of coded scenes (Bridges et al., 2010; Vannier et al., 2014).

The prevalence of penile-anal intercourse depictions in male-female pornography has varied widely in prior research, occurring in 15-56\% of coded scenes. In pornographic DVDs, anal intercourse was depicted in $46-56 \%$ of coded scenes (Bridges et al., 2010; Sun et al., 2008); in online tube videos, anal sex was found in $15-32 \%$ of coded scenes (Gorman et al., 2010; Vannier et al., 2014). In part, this difference may reflect the fact that DVDs tend to feature full scenes, whereas online tube sites feature films that have been sliced into parts, diversifying the available images into myriad categories. Fewer studies have examined the prevalence of non-genital sexual behaviors, such as kissing. One such study by Vannier et al. (2014) found that $41 \%$ of coded videos included kissing and just $4 \%$ of videos analyzed depicted sex toy use.

As researchers have yet to systematically compare the prevalence of diverse sexual behaviors in pornography with their prevalence in the population-level sexual experiences of US adults, this study aimed to address the following research question:

Research Question 1: How do individuals' sexual behaviors during their most recent male-female sexual experience compare to the depiction of sexual behaviors in male-female mainstream pornography including kissing, cunnilingus, fellatio, penile-vaginal intercourse, penile-anal intercourse, and toy use?

\section{Condom Use in Pornography}

Several content analyses have examined the prevalence of safer sex depictions in pornography. Overall, condom use in pornography tends to be rare-present in about $2 \%$ of online pornographic scenes and about $10 \%$ of pornographic DVDs (Bridges et al., 2010; Vannier et al., 2014). Condom use is a chief concern of sexual public health scholars (Albarracin et al., 2001; Reece et al., 2010; Schick et al., 2010), as sexually transmitted infections (STIs) have been consistently increasing in the USA (Centers for Disease Control \& Prevention, 2019). As condom use is critical to reducing the risk of unintended pregnancies and STIs and tends to decrease 
between adolescence and young adulthood (e.g., Reece et al., 2010), it is important to examine how the depiction of condom use in online pornography compares to Americans' selfreported behaviors.

Research Question 2: How do individuals' condom use behaviors during their most recent sexual experience compare to the depiction of condom use in pornography?

\section{Orgasm in Pornography}

Although orgasm is not a universal indicator of pleasurable sex (Chadwick et al., 2019), it is often associated with sexual pleasure and enjoyment (Opperman et al., 2014). A study by Klaassen and Peter (2015) examined the depiction of orgasm in 400 online pornographic videos and found men appeared to experience orgasm in $76 \%$ of coded scenes, compared to only 17\% for women. Fritz and Paul (2017) found a similar discrepancy in the depiction of orgasm in a sample of 100 online mainstream videos with $61 \%$ of videos depicting male orgasm, compared to just $15 \%$ for female orgasm. Researchers have found that double standards exist for men and women while hooking up; men are thought to be entitled to orgasm during a hookup, but women are not (Armstrong et al., 2012). This creates an orgasm gap between men and women, where men tend to experience orgasms significantly more often than do women, especially with newer partners (Armstrong et al., 2012; Herbenick et al., 2010). However, orgasm depictions in pornography have yet to be empirically compared to US adults' reports of orgasm.

Research Question 3: How do individuals' reported experiences of orgasm during their most recent sexual experience compare to the prevalence of male and female orgasms in pornography?

\section{Pornography Use and Sexual Partners}

Several socialization theories including sexual script theory (Gagnon \& Simon, 1973) and social cognitive theory (Bandura, 2001) suggest that individuals may learn scripts from either observing others or from various media, including learning sexual scripts from pornography. Specifically addressing sexual socialization, Wright's (2011) ${ }_{3}$ AM model of sexual socialization suggests that viewing pornography may be associated with the acquisition of new sexual behavior scripts (at least for some people, some of the time), normalizing existing sexual scripts, and engaging in viewed behaviors. Supporting this model, more frequent pornography use has been found to be positively associated with consumers' number of sexual partners, participation in adventurous sex, and age of first intercourse (Brown \& L'Engle, 2009; Hald et al., 2013; Wright \& Arroyo, 2013). A study of Swedish adolescents found that young men who were high consumers of pornography were more likely to try to act out behaviors they see in pornography (Häggström-Nordin et al., 2005). Additionally, qualitative studies have demonstrated that many young people describe learning about sexual behaviors from watching pornography and then incorporating these behaviors into their sexual repertoires (Herbenick et al., 2021; Cruz $\&$ Sheridan, 2021; Rothman et al., 2015).

Further, prior research suggests that pornography use is related to engagement in certain kinds of sex (even though it is important to note that directionality is often unable to be determined due to study methodologies). For example, Weinberg et al. (2010) found that greater pornography consumption in the past year was associated with more reported experiences with masturbation, oral sex, coitus, and anal sex. In another study, women who consumed pornography were significantly more likely to report experiencing anal sex (Tydén et al., 2001). Additionally, one experimental study found women exposed to sexually explicit media that depicted clitoral self-stimulation were more likely to report clitoral self-stimulation a week later (Kohut \& Fisher, 2013). And, in a qualitative interview study, some women and men reported first learning about choking during sex from pornography (Herbenick et al., 2021). These studies suggest that pornography (like other forms of media as well as peer and partnered interactions) may shape individuals' solo and partnered sexual repertoires.

Research related to couples' use of pornography has focused less often on sexual repertoire and more often on sexual and relationship satisfaction, with little attention paid to associations with sexual pleasure (McKee et al., 2021). Meta-analyses and reviews of studies find a small negative association between pornography use and both relationship and sexual satisfaction (Perry, 2020; Wright et al., 2017). Although little research has examined the role of pornography in couples' sexual repertoires, the ${ }_{3} \mathrm{AM}$ framework would suggest that script-situation correspondence, or the congruency between media depictions and reality, can strengthen the relationship between pornography consumption and the viewed script's activation and application (Wright, 2011). This suggests that if sexual partners were consuming pornography just before or during sexual activity, indicating congruency between media and life, the sexual scripts being consumed would be more likely to be activated and applied. Although only including men in their sample, one study found that men who watched pornography with their partner were more likely to report having engaged in oral, anal, and group sex (Træen \& Daneback, 2013). Another study of young women and men in Mozambique found that some participants described watching pornography prior to meeting a partner for sex so that they could be inspired by pornography and have ideas for sex acts readily available in their minds (Cruz \& Sheridan, 2021). As pornography consumption may lead to acquiring and performing specific scripts (at least for some people), this study sought to extend the literature by 
examining how dyads' co-viewing of pornography may be associated with their immediate sexual experience.

Research Question 4: Is there an association between couple's viewing of pornography together and the sexual experiences reported at that same sexual event (e.g., kissing, cunnilingus, fellatio, penile-vaginal intercourse, penile-anal intercourse, toy use, condom use and orgasm)?

\section{Method}

This study utilized two large and distinct datasets. The pornographic videos were sampled from a content analysis of 7430 pornographic videos taken from two free Internet pornographic tube sites, Xvideos.com and Pornhub.com in 2013 and 2014. The sample of Americans' most recent sexual experiences is from the 2014 National Survey of Sexual Health and Behavior (NSSHB-Wave 4). The total sample from the 2014 NSSHB included 2098 individuals from the nationally representative Ipsos (formerly GfK) KnowledgePanel ${ }^{\circledR}$.

\section{Sampling and Coding for the Pornographic Sample}

This study examines a subset of internet-accessible pornographic videos from Pornhub.com and Xvideos.com. Specifically, we examined 2562 video scenes categorized by the websites as "heterosexual" and that contained only one man and one woman, including 2191 from Xvideos and 371 from Pornhub. To compare the US survey sample to the pornographic sample, only videos containing one man and one woman were included in present analyses. All videos were randomly selected from Fall 2013 through Spring 2014. A single researcher utilized a systematic random sampling procedure to obtain a representative sample of content from each of the two sites. A proportionally representative number of videos were sampled from the categories found to contain the highest number of total videos on the site. This resulted in a sample representative of what a visitor was likely to be exposed to if they navigated to any of the site's most populated content categories. Further, as the content of the site homepage consists of videos posted in the various content categories, the sample is also representative of the types of videos a site visitor is likely to see upon first visiting the site. The justification for sampling and methodology has been described in more depth in Fritz et al. (2021).

Coding Procedure and Reliability. Coding was conducted by 33 trained undergraduate students. There were two groups of student coders-one group of 27 students that coded videos from Xvideos.com and a second group of six students that coded videos from Pornhub.com. Students received $20 \mathrm{~h}$ of training from the fourth author to learn the coding scheme and optimize reliability. To calculate intercoder reliability, coders applied the coding tool to 20 non-randomly selected videos. Intercoder reliability was evaluated by examining agreement among the coders on individual coding indicators. In the sexual behavior group, coders reached between 98 and 100\% agreement on all indicators of kissing, cunnilingus, fellatio, toy use-female, penile-vaginal intercourse, and penile-anal intercourse. Coders achieved a $91 \%$ level of agreement for orgasm depiction and a $95 \%$ level for condom use. After training, coders were assigned between ten and twenty videos a week for individual coding. Additional justification for reliability calculations can be found in Fritz et al. (2020).

Coding Sexual Behaviors. The following sexual behaviors were coded: kissing, toy use-female, oral, penile-vaginal, and penile-anal intercourse. The sex of sexual partners was also coded. For this study, only sexual behaviors between apparent males and females were analyzed. Kissing was defined as any contact between partners' mouths, while oral sex was any contact between a person's mouth and their partner's genitals. Penile-vaginal intercourse was penetration of the vagina by a penis. Penile-anal intercourse depicted penetration of the anus by a penis. For this analysis, toy use was any instance of a toy being used to touch or to penetrate a partner's genitals.

Coding Orgasm. Male and female orgasms were both coded on an individual level, including codes for physically explicit (squirting or penile ejaculation shown) and implicit (full body seizing, increased thrusts to climax) and verbally explicit (saying "I'm cumming") or implicit (saying "I'm going to cum") orgasms. Coders were also instructed to look for contextual clues in the title of the video such as "female squirting" or "woman orgasms," for additional evidence of female orgasm.

Coding Condom Use. Coders noted whether male participants wore a condom during oral, penile-vaginal, or penile-anal intercourse. For this study, males were coded as wearing a condom only if the condom remained on during sexual activity through ejaculation or the end of the scene. Female/internal condom use was not coded.

\section{Survey Sample: Participants}

The comparative data on the sexual behaviors of US adults were collected through the 2014 National Survey of Sexual Health and Behavior (NSSHB), conducted in Fall 2014. Of 4596 individuals screened, 2098 (45.6\%) completed the entire survey. To make a more direct comparison to the pornographic sample which includes only videos of sex between one woman and one man, this study examines a subset of the total NSSHB sample. This study examines 1262 individuals who reported on a male-female sexual experience during their most recent sexual event. Data were collected using a population-based cross-sectional survey via Ipsos KnowledgePanel ${ }^{\circledR}$ (USA). The online research panel was 
constructed based on an address-based sampling frame, which covered approximately $98 \%$ of households. Individuals were randomly selected and recruited via mailings and telephone to join the panel. The panel was weighted based on benchmarks from the March 2014 supplement of the Current Population Survey (CPS) so that the panel would be representative of the US population. A probability proportional to size procedure was used to select NSSHB participants from the panel. Those selected for recruitment were sent an email with a link to learn more about the survey and, if they agreed to participate in the survey, to click a link and proceed to take the survey. Respondents could skip any question they wished to skip. Ipsos operates a modest incentive program with raffles of cash rewards and other prizes. Poststratification weights were provided by Ipsos to further align the sample with benchmarks from the CPS including age, gender, race/ethnicity, education, census region, household income, metropolitan area, and internet access. Statistical analyses were conducted using the weighted data. All study procedures were approved by the Institutional Review Board at the author's institution. The 2014 NSSHB methodology and sampling have been described more fully in Herbenick et al. (2019).

\section{Measures}

Demographic information, such as race/ethnicity, age, and gender, was collected as part the KnowledgePanel ${ }^{\circledR}$ recruitment and retention process. Respondents were asked to reflect on their most recent sexual experience and were asked if they had kissed, given oral sex, received oral sex, had penile-vaginal intercourse, had a penis inserted into their anus/butthole, or inserted their penis into their partners' anus/ butthole (men only). Respondents were also asked if they had used a vibrator on their genitals/anus, if they had used a vibrator on their partners' genitals/anus, or if they had used some sort of other sex toy; these behaviors were coded as toy use. Each respondent was asked if they had experienced orgasm (yes-one orgasm; yes-more than one orgasm; no; not sure). Respondents were coded as experiencing an orgasm if they reported one or more orgasms. They were also asked if their partner had experienced an orgasm (using the same response options); respondents' partners were coded as experiencing orgasm if one or more orgasms were reported. Condom use was assessed using a dichotomous yes or no response to the question "Did you or your partner use a condom during this most recent act of vaginal or anal intercourse?" Additionally, respondents were asked if they had watched pornography together during their most recent sexual experience.

\section{Statistical Analysis}

Pearson's chi-squared tests were used to compare differences between descriptive data for sexual behaviors in mainstream pornography to the reported levels of sexual behaviors of NSSHB respondents in two different and equal age categories (18-44 and 45-65), as well as compared to all ages. Age groups were split at the median age (44). Total counts and percentages for the descriptive data are presented in Table 1. Pearson's chi-squared tests were also used to compare differences between individuals who reported viewing pornography with their partner and those who did not with their subsequent sexual behaviors. Total counts and percentages are presented in Table 2. Phi statistics provide indications of the effect sizes for the various chi-square tests. Effect sizes equal to 0.10 are considered small, 0.30 are medium and effect sizes greater than 0.50 are considered large (Kline, 2004). Missing data were left out of the analysis meaning not all categories of comparison have the same sample size. Significance tests were corrected using the false discovery rate (FDR) also known as the Benjamini-Hochberg procedure for controlling false discovery rates (Benjamini \& Hochberg, 1995). All analyses were conducted using SPSS version 22.0 (SPSS Inc, Chicago, Illinois).

\section{Results}

Research Question 1: How do individuals' sexual behaviors during their most recent male-female sexual experience compare to the depiction of sexual behaviors in male-female mainstream pornography including kissing, cunnilingus, fellatio, penile-vaginal intercourse, penile-anal intercourse, and toy use?

A full list of all age group comparisons to depictions in pornography can be found in Table 1 . Overall, kissing was depicted in the pornographic scenes significantly less often than reported at the event level by survey participants of all ages, $\left(\chi^{2}(2, n=3940)=1400.31, p<0.001, \phi=0.60\right)$. Also, fellatio was depicted in pornography significantly more often than was reported by survey participants across all the age groups $\left(\chi^{2}(2, n=3940)=438.59, p<0.001, \phi=-0.33\right)$. The prevalence of depictions of cunnilingus in pornography was not significantly different compared to the overall reported behaviors of the sample. Individuals aged 45-64, however, reported participating in cunnilingus at a significantly higher rate than was depicted in the pornography sample $\left(\chi^{2}(2, n=3200=8.76, p<0.01, \phi=-0.05)\right.$. Penile-vaginal intercourse was depicted less frequently in pornography than it was experienced by individuals of all age groups $\left(\chi^{2}(2\right.$, $n=3940)=57.24, p<0.001, \phi=0.12)$. Penile-anal intercourse was depicted as occurring more frequently in pornography than reported as part of individuals' last sexual 
Table 1 Comparison between sexual behaviors depicted in pornography and sexual behaviors reported in last sexual experience of Americans

\begin{tabular}{|c|c|c|c|c|}
\hline Content & Pornography & All ages & $18-45$ & $45-65$ \\
\hline \multicolumn{5}{|l|}{ Sexual behaviors } \\
\hline Kissing & $649(25 \%)$ & $\begin{array}{l}1209 * * \\
(n=1378,88 \%)\end{array}$ & $\begin{array}{l}666^{* *} \\
(n=740,90 \%)\end{array}$ & $\begin{array}{l}453 * * \\
(n=638,85 \%)\end{array}$ \\
\hline Cunnilingus & $688(27 \%)$ & $\begin{array}{l}382 \\
(n=1,377,28 \%)\end{array}$ & $\begin{array}{l}172 \\
(n=737,23 \%)\end{array}$ & $\begin{array}{l}209^{*} \\
(n=638,33 \%)\end{array}$ \\
\hline Fellatio & $1700(66 \%)$ & $\begin{array}{l}434 * * \\
(n=1378,32 \%)\end{array}$ & $\begin{array}{l}229 * * \\
(n=740,31 \%)\end{array}$ & $\begin{array}{l}205^{* *} \\
(n=638,32 \%)\end{array}$ \\
\hline Penile-vaginal sex & $1666(65 \%)$ & $\begin{array}{l}1057 * * \\
(n=1378,77 \%)\end{array}$ & $\begin{array}{l}562 * * \\
(n=740,76 \%)\end{array}$ & $\begin{array}{l}495 * * \\
(n=639,78 \%)\end{array}$ \\
\hline Penile-anal sex & $444(17 \%)$ & $\begin{array}{l}56^{* *} \\
(n=1378,4 \%)\end{array}$ & $\begin{array}{l}31 * * \\
(n=740,4 \%)\end{array}$ & $\begin{array}{l}26^{* *} \\
(n=639,4 \%)\end{array}$ \\
\hline Toy use & $159(6 \%)$ & $\begin{array}{l}117 \\
(n=1381,9 \%)\end{array}$ & $\begin{array}{l}63 \\
(n=739,9 \%)\end{array}$ & $\begin{array}{l}53 \\
(n=640,8 \%)\end{array}$ \\
\hline \multicolumn{5}{|l|}{ Sexual depiction } \\
\hline Condom use & $82(3 \%)$ & $\begin{array}{l}204 * * \\
(n=1064,19 \%)\end{array}$ & $\begin{array}{l}132 * * \\
(n=569,23 \%)\end{array}$ & $\begin{array}{l}71 * * \\
(n=494,14 \%)\end{array}$ \\
\hline Female orgasm & $317(12 \%)$ & $\begin{array}{l}895 * * \\
(n=1,382,65 \%)\end{array}$ & $\begin{array}{l}480 * * \\
(n=741,65 \%)\end{array}$ & $\begin{array}{l}414 * * \\
(n=640,65 \%)\end{array}$ \\
\hline Male orgasm & $910(36 \%)$ & $\begin{array}{l}1002 * * \\
(n=1,385,87 \%)\end{array}$ & $\begin{array}{l}657 * * \\
(n=745,88 \%)\end{array}$ & $\begin{array}{l}545 * * \\
(n=640,85 \%)\end{array}$ \\
\hline \multicolumn{5}{|c|}{$\begin{array}{l}\text { Significance tests were corrected using the false discovery rate (FDR) also known as the Ben } \\
\text { berg procedure for controlling false discovery rates (Benjamini \& Hochberg, 1995). The sa } \\
\text { pornography is always } n=2562 \text {. Sample size varies between the age groups and categori } \\
\text { missing data. The sample size is noted in each cell } \\
{ }^{* *} p<.001 \text { indicates that a category was significantly different from the pornography category }\end{array}$} \\
\hline \multicolumn{5}{|c|}{${ }^{*} p<.01$ indicates that a category was significantly different from the pornography category } \\
\hline
\end{tabular}

experience $\left(\chi^{2}(2, n=3940)=142.52, p<0.001, \phi=-0.19\right)$. Finally, the prevalence of toy use among male-female partners did not differ significantly from the depiction in pornography and overall was rare.

Research Question 2: How do individuals' condom use behaviors during their most recent sexual experience compare to the depiction of condom use in pornography?

Condom use was shown significantly less often in pornography than the level of condom use reported by individuals during their last sexual encounter, $\left(\chi^{2}(2, n=3626)=263.98\right.$, $p<0.001, \phi=0.27)$. As shown in Table 2 , we found that condom use was shown in $3 \%$ of pornographic videos yet was reported by $19 \%$ of adults at their most recent sexual event.

Research Question 3: How do individuals' reported experiences of orgasm during their most recent sexual experience compare to the prevalence of male and female orgasms in pornography?

Both female and male orgasm were depicted significantly less often in pornography than reported by respondents. Only $12 \%$ of pornographic scenes depicted female orgasm, which was significantly less than the $65 \%$ of women who reported having one or more orgasms at their most recent sexual event $\left(\chi^{2}(2, n=3944)=1157.46\right.$, $p<0.001, \phi=0.54)$. While male orgasm was depicted more often than female orgasm in pornographic scenes, it was still observed in only $36 \%$ of scenes coded, which is significantly less than the $87 \%$ of men who reported experienced orgasm at their most recent sexual event $\left(\chi^{2}(2\right.$, $n=3947)=949.85, p<0.001, \phi=0.50)$.

Research Question 4: Is there an association between couples' viewing of pornography together and the sexual experiences reported at that same sexual event (e.g., kissing, cunnilingus, fellatio, penile-vaginal intercourse, penile-anal intercourse, toy use, condom use, and orgasm)?

As shown in Table 2, dyadic pornography use was not related to participants' reports of event-level kissing or penile-vaginal intercourse. Co-viewing pornography was related, however, to the likelihood of participating in oral sex. Individuals who reported viewing pornography with their partner were more likely to report both cunnilingus $\left(\chi^{2}(2, n=1368)=14.83, p<0.001, \phi=0.10\right)$ and fellatio $\left(\chi^{2}(2, n=1370)=25.24, p<0.001, \phi=0.14\right)$ during their last sexual experience. They were also more likely to report event-level penile-anal intercourse $\left(\chi^{2}(2, n=1370)=68.45\right.$, $p<0.001, \phi=0.22)$ and sex toy use $\left(\chi^{2}(2, n=1372)=92.91\right.$, $p<0.001, \phi=0.26)$.

Co-viewing pornography was not significantly related to condom use or male orgasm $\left(\chi^{2}(2, n=1373)=5.47, p=0.02\right)$. However, dyadic pornography use at the most recent sexual event was related to a greater likelihood of female orgasm, 
Table 2 Porn consumption and dyadic sexual behaviors

\begin{tabular}{lll}
\hline Content & No porn consumption & $\begin{array}{l}\text { Dyadic porn } \\
\text { consumption }\end{array}$ \\
\hline $\begin{array}{l}\text { Sexual behaviors } \\
\text { Kissing }\end{array}$ & $\begin{array}{l}1145 \\
(n=1309,88 \%)\end{array}$ & $\begin{array}{l}56 \\
(n=61,92 \%)\end{array}$ \\
Cunnilingus & $\begin{array}{l}348^{* *} \\
(n=1307,27 \%)\end{array}$ & $\begin{array}{l}30 \\
(n=61,49 \%)\end{array}$ \\
Fellatio & $394^{* *}$ & 37 \\
& $(n=1309,30 \%)$ & $(n=61,61 \%)$ \\
Penile-vaginal sex & 1007 & 47 \\
& $(n=1309,77 \%)$ & $(n=61,77 \%)$ \\
Penile-anal sex & $41^{* *}$ & 15 \\
& $(n=1309,3 \%)$ & $(n=61,25 \%)$ \\
Toy use & $91 * *$ \\
& $(n=1310,7 \%)$ & 26 \\
Sexual depiction & & $(n=62,42 \%)$ \\
Condom use & 194 & \\
Female orgasm & $(n=1013,19 \%)$ & 10 \\
& $834^{* *}$ & $(n=48,21 \%)$ \\
Male orgasm & $(n=1310,64 \%)$ & 53 \\
& 1133 & $(n=61,87 \%)$ \\
& $(n=1312,86 \%)$ & 59 \\
& & $(n=61,97 \%)$
\end{tabular}

Significance tests were corrected using the false discovery rate (FDR) also known as the Benjamini-Hochberg procedure for controlling false discovery rates (Benjamini \& Hochberg, 1995)

${ }^{* *} p<.001$ indicates that a category was significantly different from the pornography category

${ }^{*} p<.01$ indicates that a category was significantly different from the pornography category

with $87 \%$ of women reporting orgasm during sexual events in which they and their partner had watched pornography compared to $64 \%$ of women reporting orgasm during sexual events in which they and their partner had not watched pornography together $\left(\chi^{2}(2, n=1371)=13.76, p<0.001\right.$, $\phi=0.10)$.

\section{Discussion}

This study's results suggest notable differences between the sexual behaviors portrayed in free mainstream male-female pornographic videos and the sexual behaviors reported at participants' most recent sexual event in a recent US nationally representative survey, the 2014 NSSHB. In general, the sex depicted in pornography appears to be less focused on intimacy or affection, more focused on male sexual pleasure (but not necessarily orgasm) including more often depicting penile-anal intercourse and fellatio, and less often depicting kissing, condom use, and female orgasm. This divergence between real life sex and sex depicted in mainstream pornography may reflect the fact that mainstream pornography has mostly been created for men, and often by men, and for the specific role of a perceived and rather limited male fantasy (Jensen, 2007). Much of mainstream pornography continues to be made within the narrow confines of what is sometimes described as male fantasy, thus persistently recreating a relatively narrow range of pornographic sexual scripts that diverge from the sexual realities of most Americans. This is perhaps not surprising given that a common motivation of pornography use is fantasy (and facilitation of masturbation and ejaculation) and men are more often consumers of pornography. However, it may be concerning that the fantasy of pornography is reinforced for men, while there are few avenues for other more realistic sexual scripts given the lack of quality sex education (Rabbitte \& Enriquez, 2018).

Although many sexuality education programs remain focused on abstinence-only education (SIECUS, 2021), these findings provide an empirical base for both comprehensive sexual education and pornography literacy educational programs. While these programs have often assumed differences between porn and real-life sexual behaviors, the present study provides empirical data to contextualize both pornographic videos as well as those described by survey participants. For example, this study found a sizable gap between how often kissing is shown in male-female pornographic videos (25\% of the time) compared to 2014 NSSHB respondents' eventlevel sexual repertoires ( $88 \%$ of the time). It is not clear why kissing is uncommonly depicted in pornography. After all, kissing is a common way of initiating sexual activities (Byers \& Heinlein, 1989; Clarke, 2006; O'Sullivan \& Byers, 1992). Kissing during sex is also one of the highest rated behaviors in terms of appeal, with about $86.0 \%$ of both women and men in a 2015 US nationally representative study rating it as very or somewhat appealing (Herbenick et al., 2017). Kissing has been associated with sexual satisfaction, relationship satisfaction, emotional intimacy, sexual pleasure, and arousal, as well as postcoital affection (Herbenick et al., 2019; Hughes \& Kruger, 2011; Kruger \& Hughes, 2010; Muise et al., 2014). That said, kissing is not universally included in partnered sexual behaviors in the USA and, when absent, a common reason (especially for younger people) has been that kissing would have felt too intimate of a behavior with a particular partner (Herbenick et al., 2019). Thus, the dearth of kissing in male-female pornographic videos may be an intentional marker of non-relational or less intimate sex. Alternatively, the lack of kissing may reflect stereotypes about men (who more often view pornography) as not being interested in kissing, intimacy, or romance, thereby underestimating how appealing most men (like most women) find kissing. Pornography literacy programs might utilize these findings as part of class discussions about gendered myths and stereotypes about preferences for kissing and other affectionate behaviors.

Another important area of discrepancy is pornographic depictions of oral sex in and of themselves, as well as 
compared with respondents' reports. Specifically, we found that fellatio was depicted in the videos more than twice as often as cunnilingus. This is consistent with earlier research demonstrating that sexual behaviors that prioritize male sexual pleasure (such as fellatio) are more often shown in pornography compared to sexual behaviors (such as cunnilingus) that focus on female sexual pleasure (Bridges et al., 2010). In fact, in this study, occurrences of fellatio were as prevalent as depictions of penile-vaginal intercourse $(66 \%$ vs. $65 \%$, respectively). While fellatio tends to be reported more often than cunnilingus among adolescents and young adults, this gender gap appears smaller among middle age cohorts (Herbenick et al., 2010; Woods et al., 2016), and consistent with our findings. Notably, both male and female orgasm were depicted less often in pornography in comparison with survey participants' reports, though male orgasm was still depicted in pornography scenes three times as often as female orgasm (36\% vs. $12 \%$ scenes, respectively). The most likely explanation for the low prevalence of orgasms included in scenes-even in contrast to older pornographic images from DVDs or videotapes-is that contemporary Internet-based pornographic scenes tend to be cut into much shorter scenes taken from longer videos. Yet, findings are generally consistent with prior content analyses of pornography (Klaassen \& Peter, 2015) as well as past population-level studies of sexual behavior that have found male orgasm to be more prevalent than female orgasm in male-female partnered sex (Herbenick et al., 2010). These findings may be useful for clinicians to use in support of clients who are working to understand how to create more equitable and reciprocal sexual partnerships; they may also be useful for sexuality educators in addressing gendered experiences of sex in and outside of pornographic imagery.

Although depicted less frequently than kissing or oral sex, penile-anal intercourse occurred in almost 1 in 5 pornographic scenes, which is significantly higher than the $4 \%$ of survey participants who reported penile-anal intercourse in their most recent sexual encounter. An examination of research on anal sex behaviors demonstrates that while many US adults (about 40\%) have engaged in anal sex ever in their lives, far fewer engage in it with much frequency or even rate it as appealing - that is, at least among those identifying as heterosexual or reporting other-sex partners (Herbenick et al., 2010, 2017; McBride \& Fortenberry, 2010). Clinicians and educators (particularly those who integrate media literacy into their teaching) might find these data support discussions about what people perceive as "common" or even nearly ubiquitous behaviors and why. Although beyond the scope of this paper, it is important to note that pornography literacy programs should be sexually inclusive and discuss the social norms surrounding penile-anal intercourse for men who have sex with men, for whom anal sex is more commonly and more frequently reported in US probability surveys (Dodge et al.,
2016). Our study findings collectively support inquiry into how people learn about sex, including which sexual behaviors are rare or common or may be anticipated by potential sexual partners, especially in a culture that drastically limits school-based sexuality education.

Regarding condom use, we found that only $3 \%$ of video scenes showed a condom being used, consistent with prior research about condom use in heterosexual films (Grudzen et al., 2009). Yet, more than six times as many survey participants reported having used a condom during their most recent intercourse event. As for why condom use is so rarely depicted in pornographic videos, some producers have expressed concern that showing condom application or use would not be liked by the largely male viewership (e.g., might be a turn-off). However, a study of 213 undergraduate men found substantial support for condoms being used in pornography (Kraus \& Rosenberg, 2016), suggesting ways for producers of pornography to provide content their viewers indicate wanting to see. This is important given recent increases in STIs in the USA, including evidence of the novel coronavirus-19 in feces and conflicting evidence of its presence in semen (Li et al., 2020; Machado et al., 2021; Nouri-Vaskeh \& Alizadeh, 2020; Song et al., 2020). In contrast, a recent study of gay male pornography found that while $34 \%$ of scenes depicted unprotected penile-anal sex, $36 \%$ of scenes depicted penile-anal sex with a condom (Downing et al., 2014), suggesting a different standard, cultural norm, and safe sex script within heterosexual versus gay pornography.

\section{Dyadic Pornography Use}

Examining how partnered pornography consumption may be associated with sexual behaviors, this study found that individuals who consumed pornography with their partner before or during sex reported engaging in significantly more fellatio and penile-anal intercourse, two sexual behaviors more frequently depicted in pornography compared to real life. This finding is in line with Wright's (2011) model of sexual socialization; partners who watch pornography together may experience more script-situation correspondence and thus may be more likely to follow scripts in pornography. Particularly considering penile-anal intercourse, one quarter of survey respondents who consumed pornography together with their partner also reported engaging in anal sex with that partner. Given that this sexual behavior is infrequently enacted between women and men, perhaps couples who consume pornography together are more familiar with seeing anal sex, which is depicted in about one in five pornographic scenes. Alternatively, couples who have a broader sexual repertoire (one that more often includes anal sex) may also be more likely to watch pornography with a partner. It is also unknown to what extent the anal intercourse, for example, was fully wanted or enjoyed by both partners. It is possible 
that some portion of these anal sex events occurred as a result of gendered power imbalances, pressure or coercion, which is frequently noted in research on women's experiences with penile-anal intercourse (Fahs et al., 2015; Hess et al., 2013; Kaestle, 2009; Rogala \& Tydén, 2003). Subsequent research might examine to what extent partnered viewing of pornography and anal sex (as well as other kinds of sex) are associated due to perceived pressure as compared to reasons such as curiosity, desire, and/or pleasure.

Regarding the findings on partnered pornography use, however, some findings did not completely align with theoretical predictions. For example, individuals who reported partnered pornography use were also more likely to report both cunnilingus and female orgasm. While cunnilingus was portrayed less frequently than fellatio in pornographic scenes, it was depicted in similar rates to survey participants' reports. Yet for individuals who consumed pornography with their partner, almost 50\% reported engaging in cunnilingus. Perhaps related, more individuals who watched pornography with their partner also reported female orgasm (87\% vs. $64 \%$ ). Research does suggest that, for women, cunnilingus is related to orgasm (Andrejek \& Fetner, 2019). Instead of simply mimicking depicted behaviors, couples may be engaging in a wider variety of sexual behaviors, which has been associated with greater likelihood of orgasm (Herbenick et al., 2010). As Weinberg et al. (2010) found, pornography may normalize previously unknown sexual behaviors such as cunnilingus or empower couples to explore other behaviors. From the female partner's perspective, one study found that women who consumed pornography were more easily aroused during partnered sex compared to those who did not view pornography (McNabney et al., 2020). Indeed, viewing pornography with a partner may allow women the opportunity to share their own desires and possibly expand their sexual repertoire to include sexual behaviors focused on clitoral or vulvar stimulation. While pornography depictions do appear to favor male pleasure, it appears that individuals' partnered use of pornography is also associated with sexual behaviors commonly associated with female sexual pleasure and orgasm.

Notably, there was no difference reported in kissing between those who reported dyadic pornography use and those who did not. This suggests that couples' pornography use may not lead to a less intimate experience even though kissing is rarely included in pornographic videos. While prior research suggests pornography consumption by individuals is associated with lower levels of couples' sexual and relationship satisfaction, our research suggests that co-viewing pornography may be a part of, or even facilitate, couples' sexual exploration and female pleasure. It may be that co-viewing pornography allows couples to talk about sexual desires or negotiate sex in a way that separate viewing of pornography does not. Subsequent research might examine how sexual partners initiate co-viewing, how they feel about it, and the extent to which they feel it contributes to their experiences of sexual pleasure, thus addressing an important gap in research (McKee et al., 2021).

\section{Strengths and Limitations}

The present study is marked by several strength and limitations. A significant strength of this research is the sampling. This study used a content analysis of randomly sampled male-female pornographic videos from two popular tube sites and analyzed data from a US nationally representative probability survey to examine male-female partnered sexual behaviors in the general population. Data collection occurred close in time with the videos sampled in Fall 2013 and Spring 2014 and the survey administered in Fall/Winter 2014. The sheer number of videos sampled (2562) makes the present content analysis one of the largest conducted to date. However, the pornography sample came from only two websites which, while highly trafficked, may have yielded different behavioral data than if other websites had been sampled. Additionally, the online videos are generally shorter than full length pornographic DVDs, and thus, caution should be exercised in comparing this study's findings to earlier research that used full-length scenes from DVDs or videotapes for the level of analysis.

Regarding the US probability survey, it was (like most US nationally representative surveys) limited to non-institutionalized individuals who were able to read and respond to questions in the English language. The size of certain subsample groups, such as individuals reporting dyadic pornography together, was relatively low. Any conclusions drawn from analysis of such data must acknowledge the lack of statistical power involved when undertaking certain comparisons. The present analysis is also limited to male-female videos and male-female partnered sex; subsequent work might examine similar research questions with different gender compositions (including male-male, female-female, transgender individuals, group sex, etc.) for video content analyses as well as adults' survey responses.

\section{Conclusions}

This study provides important data for clinicians and sexuality educators (and particularly those including pornography literacy into their curricula), about several discrepancies between the prevalence of certain sexual behaviors shown in contemporary online pornography and those same sexual behaviors as reported by individuals in a US nationally representative probability survey. These findings provide empirical evidence to what is already a much-reported fact in popular media: porn sex is different from real sex. Additionally, this study found a relationship between dyadic viewing of 
pornography and event-level sexual repertoire in ways that suggest viewing pornography with a partner may be associated with sexual variety and orgasm.

Acknowledgements Our title pays homage to Cindy Gallop's Make Love Not Porn TED talk, which references "Porn World vs. Real World" differences as well as the popular 2013 video, "Porn Sex vs. Real Sex: The Differences Explained with Food. The authors are grateful to Church \& Dwight Co. Inc., makers of Trojan sexual health brand products, for their support of the 2014 National Survey of Sexual Health and Behavior.

\section{Compliance with Ethical Standards}

Conflict of interest The 2014 NSSHB data were collected as part of a study funded by Church \& Dwight Co., Inc. (PIS: Herbenick and Reece).

Ethical approval The sexually explicit media content analysis did not contain human subjects. Study protocols and instruments for the 2014 NSSHB were reviewed and approved by the Institutional Review Board at Indiana University (Protocol \#1408833205).

Informed consent Participants in the 2014 NSSHB provided consent prior to survey completion.

\section{References}

Albarracin, D., Johnson, B. T., Fishbein, M., \& Muellerleile, P. A. (2001). Theories of reasoned action and planned behavior as models of condom use: A meta-analysis. Psychological Bulletin, 127, 142-161.

Allen, M., D'alessio, D., \& Brezgel, K. (1995). A meta-analysis summarizing the effects of pornography II aggression after exposure. Human Communication Research, 22, 258-283.

Andrejek, N., \& Fetner, T. (2019). The gender gap in orgasms: Survey data from a mid-sized Canadian city. International Journal of Sexual Health, 31, 26-35.

Armstrong, E. A., England, P., \& Fogarty, A. C. (2012). Accounting for women's orgasm and sexual enjoyment in college hookups and relationships. American Sociological Review, 77, 435-462.

Arrington-Sanders, R., Harper, G. W., Morgan, A., Ogunbajo, A., Trent, M., \& Fortenberry, J. D. (2015). The role of sexually explicit material in the sexual development of same-sex-attracted Black adolescent males. Archives of Sexual Behavior, 44(3), 597-608.

Attwood, F., Smith, C., \& Barker, M. (2018). 'I'm just curious and still exploring myself': Young people and pornography. New Media \& Society, 20, 3738-3759.

Baams, L., Overbeek, G., Dubas, J. S., Doornwaard, S. M., Rommes, E., \& Van Aken, M. A. (2015). Perceived realism moderates the relation between sexualized media consumption and permissive sexual attitudes in Dutch adolescents. Archives of Sexual Behavior, 44, 743-754.

Bandura, A. (2001). Social cognitive theory of mass communication. Media Psychology, 3, 265-299.

Benjamini, Y., \& Hochberg, Y. (1995). Controlling the false discovery rate: a practical and powerful approach to multiple testing. Journal of the Royal Statistical Society Series B (Methodological), 57, 289-300.
Bridges, A. J., Wosnitzer, R., Scharrer, E., Sun, C., \& Liberman, R. (2010). Aggression and sexual behavior in best-selling pornography videos: A content analysis update. Violence against Women, $16,1065-1085$.

Bronstein, C. (2011). Battling pornography: The American feminist anti-pornographymovement, 1976-1986. Cambridge University Press.

Brown, J. D., \& L'Engle, K. L. (2009). X-rated sexual attitudes and behaviors associated with US early adolescents' exposure to sexually explicit media. Communication Research, 36, 129-151.

Byers, E. S., \& Heinlein, L. (1989). Predicting initiations and refusals of sexual activities in married and cohabitating heterosexual couples. Journal of Sex Research, 26, 210-231.

Centers for Disease Control and Prevention. (2019). Sexually Transmitted Disease Surveillance2018. U.S. Department of Health and Human Services. https://doi.org/10.15620/cdc.79370. Retrieved from https://www.cdc.gov/std/stats18/default.htm

Chadwick, S. B., Francisco, M., \& van Anders, S. M. (2019). When orgasms do not equal pleasure: Accounts of "bad" orgasm experiences during consensual sexual encounters. Archives of Sexual Behavior, 48, 2435-2459.

Clarke, L. H. (2006). Older women and sexuality: Experiences in marital relationships across the life course. Canadian Journal on Aging / La Revue Canadienne du Vieillissement, 25, 129-140.

Corsianos, M. (2007). Mainstream pornography and "women": Questioning sexual agency. Critical Sociology, 33, 863-885.

Cruz, G. V., \& Sheridan, T. (2021). The normalization of violence during sex among young Mozambicans reportedly under the influence of pornography. Sexuality and Culture. https://doi. org/10.1007/s12119-021-09898-7

Davis, A. C., Temple-Smith, M. J., Carrotte, E., Hellard, M. E., \& Lim, M. S. C. (2020). A descriptive analysis of young women's pornography use: A tale of exploration and harm. Sexual Health, 17, 69-76.

Dawson, K., Gabhainn, S. N., \& MacNeela, P. (2020). Toward a model of porn literacy: Core concepts, rationales, and approaches. Journal of Sex Research, 57, 1-15.

Dodge, B., Herbenick, D., Fu, T. C. J., Schick, V., Reece, M., Sanders, S., \& Fortenberry, J. D. (2016). Sexual behaviors of US men by self-identified sexual orientation: Results from the 2012 National Survey of Sexual Health and Behavior. Journal of Sexual Medicine, 13, 637-649.

Downing, M. J., Schrimshaw, E. W., Antebi, N., \& Siegel, K. (2014). Sexually explicit media on the Internet: A content analysis of sexual behaviors, risk, and media characteristics in gay male adult videos. Archives of Sexual Behavior, 43, 811-821.

Fahs, B., Swank, E., \& Clevenger, L. (2015). Troubling anal sex: Gender, power, and sexual compliance in heterosexual experiences of anal intercourse. Gender Issues, 32, 19-38.

Fritz, N., Malic, V., Paul, B., \& Zhou, Y. (2020). A descriptive analysis of the types, targets, and relative frequency of aggression in mainstream pornography. Archives of Sexual Behavior, 49(8), 3041-3053.

Fritz, N., Malic, V., Paul, B., \& Zhou, Y. (2021). Worse than objects: The depiction of black women and men and their sexual relationship in pornography. Gender Issues, 38, 100-120. https://doi.org/ 10.1007/s12147-020-09255-2

Fritz, N., \& Paul, B. (2017). From orgasms to spanking: A content analysis of the agentic and objectifying sexual scripts in feminist, for women, and mainstream pornography. Sex Roles, 77, 639-652.

Gagnon, J. H., \& Simon, W. (1973). Sexual conduct: The social sources of human sexuality. Transaction Publishers.

Gallop, C. (2009). Make love, not porn. Retrieved from https://www. ted.com/talks/cindy_gallop_make_love_not_porn 
Gorman, S., Monk-Turner, E., \& Fish, J. N. (2010). Free adult internet web sites: How prevalent are degrading acts? Gender Issues, 27, 131-145.

Grudzen, C. R., Elliott, M. N., Kerndt, P. R., Schuster, M. A., Brook, R. H., \& Gelberg, L. (2009). Condom use and high-risk sexual acts in adult films: A comparison of heterosexual and homosexual films. American Journal of Public Health, 99, S152-S156.

Häggström-Nordin, E., Hanson, U., \& Tydén, T. (2005). Associations between pornography consumption and sexual practices among adolescents in Sweden. International Journal of STD and AIDS, $16,102-107$.

Hald, G. M. (2006). Gender differences in pornography consumption among young heterosexual Danish adults. Archives of Sexual Behavior, 35, 577-585.

Hald, G. M., Kuyper, L., Adam, P. C., \& Wit, J. B. (2013). Does viewing explain doing? Assessing the association between sexually explicit materials use and sexual behaviors in a large sample of Dutch adolescents and young adults. The Journal of Sexual Medicine, 10, 2986-2995.

Hald, G. M., \& Malamuth, N. M. (2008). Self-perceived effects of pornography consumption. Archives of Sexual Behavior, 37(4), 614-625.

Hald, G. M., Malamuth, N. M., \& Yuen, C. (2010). Pornography and attitudes supporting violence against women: Revisiting the relationship in nonexperimental studies. Aggressive Behavior, $36,14-20$.

Heins, M. (2007). Not in front of the children: "Indecency," censorship, and the innocence of youth. Rutgers University Press.

Herbenick, D., Bowling, J., Fu, T. C. J., Dodge, B., Guerra-Reyes, L., \& Sanders, S. A. (2017). Sexual diversity in the United States: Results from a nationally representative probability sample of adult women and men. PLOS ONE, 12, e0181198.

Herbenick, D., Fu, T. C., Owens, C., Bartelt, E., Dodge, B., Reece, M., \& Fortenberry, J. D. (2019). Kissing, cuddling, and massage at most recent sexual event: Findings from a U.S. nationally representative probability sample. Journal of Sex and Marital Therapy, 45, 159-172.

Herbenick, D., Fu, T. C., Wright, P., Paul, B., Gradus, R., Bauer, J., \& Jones, R. (2020). Pornography use and diverse sexual behaviors: Findings from a nationally representative survey of Americans ages 14 to 60. Journal of Sexual Medicine, 17, 623-633.

Herbenick, D., Guerra-Reyes, L., Patterson, C., Rosenstock Gonzalez, Y. R., Wagner, C., \& Zounlome, N. (2021). "It was scary, but then it was kind of exciting": Young women's experiences with choking during sex. Archives of Sexual Behavior. https://doi.org/ 10.1007/s10508-021-02049-x

Herbenick, D., Reece, M., Schick, V., Sanders, S. A., Dodge, B., \& Fortenberry, J. D. (2010). An event-level analysis of the sexual characteristics and composition among adults ages 18 to 59: Results from a national probability sample in the United States. Journal of Sexual Medicine, 7, 346-361.

Hess, K. L., Javanbakht, M., Brown, J. M., Weiss, R. E., Hsu, P., \& Gorbach, P. M. (2013). Intimate partner violence and anal intercourse in young adult heterosexual relationships. Perspectives on Sexual and Reproductive Health, 45, 6-12.

Hughes, S. M., \& Kruger, D. J. (2011). Sex differences in post-coital behaviors in long- and short-term mating: An evolutionary perspective. Journal of Sex Research, 48, 496-505.

Jensen, R. (2007). Getting off: Pornography and the end of masculinity. South End Press.

Kaestle, C. E. (2009). Sexual insistence and disliked sexual activities in young adulthood: Differences by gender and relationship characteristics. Perspectives on Sexual and Reproductive Health, 41, 33-39.
KB Creative Lab. (2013). 'Porn sex vs real sex: The differences explained with food.' Accessed September 25, 2021. http:// www.youtube.com/watch?v=q64hTNEj6KQ

Klaassen, M. J., \& Peter, J. (2015). Gender (in) equality in internet pornography: A content analysis of popular pornographic internet videos. Journal of Sex Research, 52, 721-735.

Kline, R. B. (2004). Beyond significance testing: Reforming data analysis methods in behavioral research. American Psychological Association.

Kohut, T., \& Fisher, W. A. (2013). The impact of brief exposure to sexually explicit video clips on partnered female clitoral selfstimulation, orgasm and sexual satisfaction. Canadian Journal of Human Sexuality, 22, 40-50.

Kraus, S. W., \& Rosenberg, H. (2016). Lights, camera, condoms! Assessing college men's attitudes toward condom use in pornography. Journal of American College Health, 64, 139-146.

Kruger, D. J., \& Hughes, S. (2010). Variation in reproductive strategies influences post-coital experiences with partners. Journal of Social, Evolutionary, and Cultural Psychology, 4, 254-264.

Li, D., Jin, M., Bao, P., Zhao, W., \& Zhang, S. (2020). Clinical characteristics and results of semen tests among men with coronavirus disease 2019. JAMA Network Open, 3, e208292-e208292.

Lindberg, L. D., Maddow-Zimet, I., \& Boonstra, H. (2016). Changes in adolescents' receipt of sex education, 2006-2013. Journal of Adolescent Health, 58, 621-627.

Litsou, K., Graham, C., \& Ingham, R. (2021). Women in relationships and their pornography use: A systematic review and thematic synthesis. Journal of Sex \& Marital Therapy, 47(4), 381-413.

Löfgren-Mårtenson, L., \& Månsson, S. A. (2010). Lust, love, and life: A qualitative study of Swedish adolescents' perceptions and experiences with pornography. Journal of Sex Research, 47, 568-579.

Luder, M. T., Pittet, I., Berchtold, A., Akré, C., Michaud, P. A., \& Surís, J. C. (2011). Associations between online pornography and sexual behavior among adolescents: Myth or reality? Archives of Sexual Behavior, 40, 1027-1035.

Maas, M. K., Vasilenko, S. A., \& Willoughby, B. J. (2018). A dyadic approach to pornography use and relationship satisfaction among heterosexual couples: The role of pornography acceptance and anxious attachment. Journal of Sex Research, 55, 772-782.

Machado, B., Barcelos Barra, G., Scherzer, N., Massey, J., dos Santos Luz, H., Henrique Jacomo, R., Rita, H. S. T., \& Davis, R. (2021). Presence of SARS-CoV-2 RNA in semen-Cohort study in the United States COVID-19 positive patients. Infectious Disease Reports, 13(1), 96-101.

McBride, K. R., \& Fortenberry, J. D. (2010). Heterosexual anal sexuality and anal sex behaviors: A review. Journal of Sex Research, 47, 123-136.

McKay, K., Poulin, C., \& Muñoz-Laboy, M. (2021). Claiming public health crisis to regulate sexual outlets: A critique of the state of Utah's declaration on pornography [Commentary]. Archives of Sexual Behavior, 50(2), 401-405.

McKee, A., Litsou, K., Byron, P., \& Ingham, R. (2021). The relationship between consumption of pornography and sexual pleasure: Results of a mixed-method systematic review. Porn Studies, 8(3), 341-344. https://doi.org/10.1080/23268743.2021.1891564

McNabney, S. M., Hevesi, K., \& Rowland, D. L. (2020). Effects of pornography use and demographic parameters on sexual response during masturbation and partnered sex in women. International Journal of Environmental Research and Public Health, 17, 3130.

Muise, A., Giang, E., \& Impett, E. A. (2014). Post sex affectionate exchanges promote sexual and relationship satisfaction. Archives of Sexual Behavior, 43, 1391-1402.

Nelson, K. M., \& Rothman, E. F. (2020). Should public health professionals consider pornography a public health crisis? American Journal of Public Health, 110, 151-153. https://doi.org/10.2105/ AJPH.2019.305498 
Nouri-Vaskeh, M., \& Alizadeh, L. (2020). Fecal transmission in COVID-19: A potential shedding route [Letter to the Editor]. Journal of Medical Virology, 92, 1331-1332.

Oddone-Paolucci, E., Genuis, M., \& Violato, C. (2000). A meta-analysis of the published research on the effects of pornography. In C. Violato, E. Oddone-Paolucci, \& M. Genuis (Eds.), The changing family and child development (pp. 48-59). Ashgate Publishing Ltd.

Opperman, E., Braun, V., Clarke, V., \& Rogers, C. (2014). "It feels so good it almost hurts": Young adults' experiences of orgasm and sexual pleasure. Journal of Sex Research, 51, 503-515.

O’Sullivan, L. F., \& Byers, E. S. (1992). College students' incorporations of initiators and restrictor roles in sexual dating interactions. Journal of Sex Research, 29, 435-446.

Paul, B., \& Shim, J. W. (2008). Gender, sexual affect, and motivations for Internet pornography use. International Journal of Sexual Health, 20, 187-199.

Perry, S. L. (2020). Pornography and relationship quality: Establishing the dominant pattern by examining pornography use and 31 measures of relationship quality in 30 national surveys. Archives of Sexual Behavior, 49, 1199-1213.

Peter, J., \& Valkenburg, P. M. (2010). Processes underlying the effects of adolescents' use of sexually explicit internet material: The role of perceived realism. Communication Research, 37, 375-399.

Pornhub 2014 Year in Review. (2015). Pornhub insights. Retrieved May 30, 2020 from https://www.pornhub.com/insights/ 2014-year-in-review

Rabbitte, M., \& Enriquez, M. (2018). The role of policy on sexual health education in schools. Journal of School Nursing, 35, 27-38. https://doi.org/10.1177/1059840518789240

Rasmussen, K. (2016). A historical and empirical review of pornography and romantic relationships: Implications for family researchers. Journal of Family Theory \& Review, 8(2), 173-191.

Reece, M., Herbenick, D., Schick, V., Sanders, S. A., Dodge, B., \& Fortenberry, J. D. (2010). Condom use rates in a national probability sample of males and females ages 14 to 94 in the United States. Journal of Sexual Medicine, 7, 266-276.

Regnerus, M., Gordon, D., \& Price, J. (2016). Documenting pornography use in America: A comparative analysis of methodological approaches. Journal of Sex Research, 53, 873-881.

Rogala, C., \& Tydén, T. (2003). Does pornography influence young women's sexual behavior? Women's Health Issues, 13, 39-43.

Rothman, E. F., Beckmeyer, J. J., Herbenick, D., Fu, T. C., Dodge, B., \& Fortenberry, J. D. (2021). The prevalence of using pornography for information about how to have sex: Findings from a nationally representative survey of U.S. adolescents and young adults. Archives of Sexual Behavior, 50(2), 629-646.

Rothman, E. F., Daley, N., \& Alder, J. (2020). A pornography literacy program for adolescents. American Journal of Public Health, $110,154-156$.

Rothman, E. F., Kaczmarsky, C., Burke, N., Jansen, E., \& Baughman, A. (2015). "Without porn... I wouldn't know half the things I know now": A qualitative study of pornography use among a sample of urban, low-income, black and Hispanic youth. Journal of Sex Research, 52, 736-746.

Schick, V., Herbenick, D., Reece, M., Sanders, S. A., Dodge, B., Middlestadt, S. E., \& Fortenberry, J. D. (2010). Sexual behaviors, condom use, and sexual health of Americans over 50: Implications for sexual health promotion for older adults. Journal of Sexual Medicine, 7, 315-329.

SIECUS. (2021). 2021 State of sex education legislative overview. Accessed on September 25, 2021 from: https://siecus.org/wpcontent/uploads/2021/01/SIECUS-2021-State-of-Sex-Ed-Legis lative-Overview.pdf

Simon, L., \& Daneback, K. (2013). Adolescents' use of the internet for sex education: A thematic and critical review of the literature. International Journal of Sexual Health, 25, 305-319.
Smith, C., Barker, M., \& Attwood, F. (2015). Why do people watch porn? Results from Pornresearch.Org. In L. Comella \& S. Tarrant (Eds.), New views on pornography: Sexuality, politics, and the law (pp. 277-296). Santa Barbara, CA: Praeger.

Song, C., Wang, Y., Li, W., Hu, B., Chen, G., Xia, P., et al. (2020). Absence of 2019 novel coronavirus in semen and testes of COVID-19 patients. Biology of Reproduction, 103(1), 4-6.

Sun, C., Bridges, A., Wosnitzer, R., Scharrer, E., \& Liberman, R. (2008). A comparison of male and female directors in popular pornography: What happens when women are at the helm? Psychology of Women Quarterly, 32, 312-325.

Tokunaga, R. S., Wright, P. J., \& Vangeel, L. (2020). Is pornography consumption a risk factor for condomless sex? Human Соттиnication Research, 46, 273-299.

Træen, B., \& Daneback, K. (2013). The use of pornography and sexual behaviour among Norwegian men and women of differing sexual orientation. Sexologies, 22, e41-e48.

Tydén, T., Olsson, S. E., \& Häggström-Nordin, E. (2001). Improved use of contraceptives, attitudes toward pornography, and sexual harassment among female university students. Women's Health Issues, 11, 87-94.

Vandenbosch, L., \& van Oosten, J. M. (2017). The relationship between online pornography and the sexual objectification of women: The attenuating role of porn literacy education. Journal of Communication, 67, 1015-1036.

Vannier, S. A., Currie, A. B., \& O’Sullivan, L. F. (2014). Schoolgirls and soccer moms: A content analysis of free "teen" and "MILF" online pornography. Journal of Sex Research, 51, 253-264.

Weinberg, M. S., Williams, C. J., Kleiner, S., \& Irizarry, Y. (2010). Pornography, normalization, and empowerment. Archives of Sexual Behavior, 39, 1389-1401.

Wood, J. R., McKay, A., Komarnicky, T., \& Milhausen, R. R. (2016). Was it good for you too?: An analysis of gender differences in oral sex practices and pleasure ratings among heterosexual Canadian university students. Canadian Journal of Human Sexuality, 25, 21-29.

Wright, P. J. (2011). 14 mass media effects on youth sexual behavior assessing the claim for causality. Communication Yearbook, 35, 343-385.

Wright, P. J., \& Arroyo, A. (2013). Internet pornography and US women's sexual behavior: Results from a national sample. Mass Communication and Society, 16, 617-638.

Wright, P. J., Bae, S., \& Funk, M. (2013). United States women and pornography through four decades: Exposure, attitudes, behaviors, individual differences. Archives of Sexual Behavior, 42, $1131-1144$

Wright, P. J., Herbenick, D., \& Paul, B. (2020). Adolescent condom use, parent-adolescent sexual health communication, and pornography: Findings from a U.S. probability sample. Health Communication, 35, 1576-1582. https://doi.org/10.1080/10410236. 2019.1652392

Wright, P. J., Sun, C., \& Steffen, N. (2018). Pornography consumption, perceptions of pornography as sexual information, and condom use. Journal of Sex and Marital Therapy, 44, 800-805.

Wright, P. J., Sun, C., Steffen, N. J., \& Tokunaga, R. S. (2015a). Pornography, alcohol, and male sexual dominance. Communication Monographs, 82, 252-270.

Wright, P. J., \& Tokunaga, R. S. (2016). Men's objectifying media consumption, objectification of women, and attitudes supportive of violence against women. Archives of Sexual Behavior, 45, 955-964.

Wright, P. J., Tokunaga, R. S., \& Kraus, A. (2015b). A meta-analysis of pornography consumption and actual acts of sexual aggression in general population studies. Journalof Communication, $66,183-205$ 
Wright, P. J., Tokunaga, R. S., \& Kraus, A. (2016). Consumption of pornography, perceived peer norms, and condom less sex. Health Communication, 31, 954-963.

Wright, P. J., Tokunaga, R. S., Kraus, A., \& Klann, E. (2017). Pornography consumption and satisfaction: A meta-analysis. Human Communication Research, 43, 315-343.
Publisher's Note Springer Nature remains neutral with regard to jurisdictional claims in published maps and institutional affiliations. 